\title{
Compaixão e Terror em Poética 1449b
}

\author{
José Gonçalves Poddis \\ Programa de Pós-Graduação em Letras: \\ Estudos Literários - FALE/UFMG \\ jpoddis@hotmail.com
}

\section{ABSTRACT:}

This paper is a brief commentary on the words "fear" and "pity", which define the tragedy in Aristotle's Poetics, and its occurrence in tragic texts. The aim is to get a statistical occurrence of these terms in order to clarify Aristotle's understanding of this poetical style, and its use by playwrights of the fifth century BC.

KEYWORD: Aristotle; Poetic; tragedy; fear; pity.

Propomos neste trabalho analisarmos a definição do gênero trágico encontrado no capítulo seis da Poética de Aristóteles ${ }^{1}$, particularmente em relação às emoções de compaixão e terror provocadas pela tragédia. Como essa foi sendo elaborado pelo autor nos primeiros capítulos da referida obra e será melhor explicada nos posteriores; nossa análise desta irá necessariamente referir-se tanto a este capítulo, quanto a conceitos mais gerais apresentados na Poética.

Segundo Dupont-Roc e Lallot, a Poética é essencialmente o estudo da tragédia e

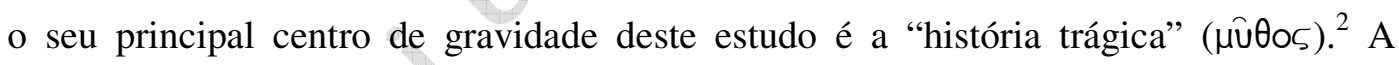
tragédia, a épica e em menor grau a comédia são os gêneros poéticos examinados neste tratado de Aristóteles, que os caracteriza por obras miméticas.

A formulação de Aristóteles a seguir têm a tradução de Ana Maria Valente, ${ }^{3}$ cujas opções serão discutidas ao longo do trabalho:

A tragédia é a imitação de uma ação elevada e completa, dotada de extensão, numa linguagem embelezada por formas diferentes em cada

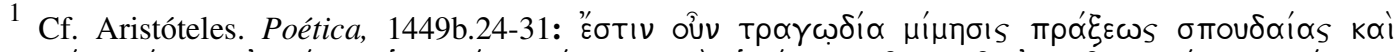

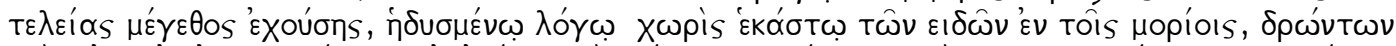

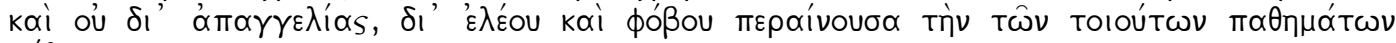

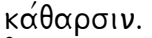

${ }^{2}$ Cf. palavras de Dupont-Roc e Lallot in Aristote. La Poétique. Texte, traduction et notes par Roselyne Dupont-Roc et Jean Lallot. Paris: Seuil, 1980, p. 14.

${ }^{3}$ Cf. Aristóteles. A Poética de Aristóteles. Tradução e notas de Ana Maria Valente, prefácio de Maria Helena da Rocha Pereira. Lisboa: Calouste Gulbenkian, 2007.
} 
uma das suas partes, que se serve da ação e não da narração e que, por meio da compaixão e do temor, provoca a purificação de tais paixões. ${ }^{4}$

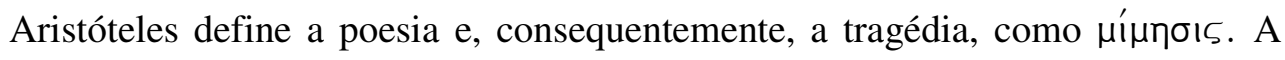

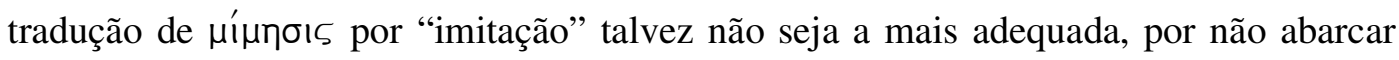
todos os sentidos os quais Aristóteles emprega, embora haja outros autores que também

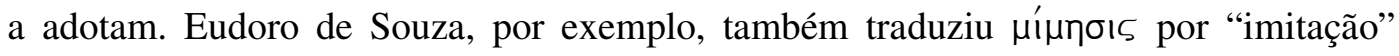
com um alerta para a ambigüidade do termo em grego, e mesmo na língua portuguesa. ${ }^{5}$

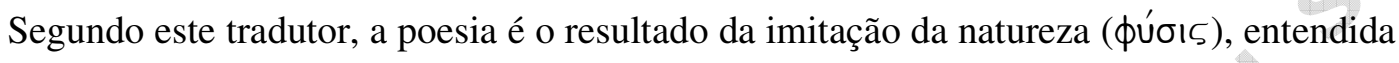
como "o oculto princípio da geração e da corrupção de todos os seres naturais e a própria realidade enquanto se realiza" ${ }^{6}$ Essa noção de realidade espelhada pela poesia não deixa de ser uma resposta ao lugar menor relegado a ela por seu mestre Platão, principalmente aos enunciados na República (VIII e X). ${ }^{7}$ Dentro da filosofia platônica, a poesia é uma “cópia” (“não-Ser”) da "natureza” ("Ser”) que é, por seu turno, uma cópia da "idéia".

Dupont-Roc e Lallot também reconhecem a influência de Platão, ${ }^{8}$ que distingue,

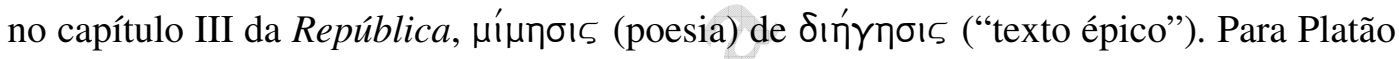

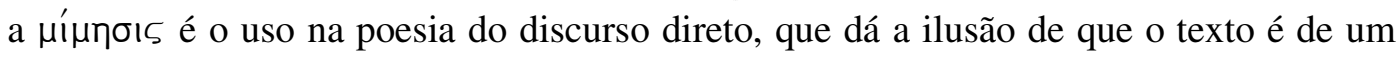

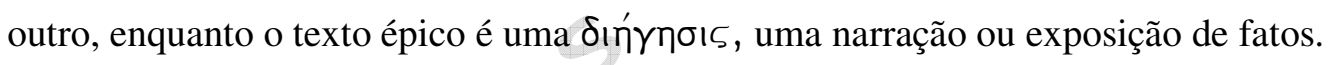

Aristóteles não vai opor poesia e épica em termos de graus de $\mu^{\prime} \mu \eta \sigma ı \zeta$, mas em termos de "modo", ou seja, a existência do espetáculo na poesia e não na épica. Esses

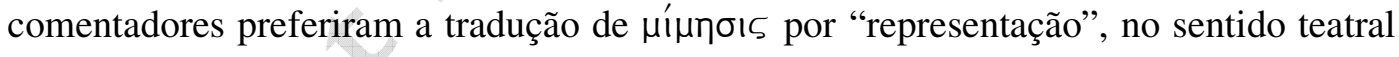
do termo e de outras palavras que compõem sua família: $:^{9}$ o agente $\mu ı \mu \tau \eta \dot{\zeta}$, o verbo

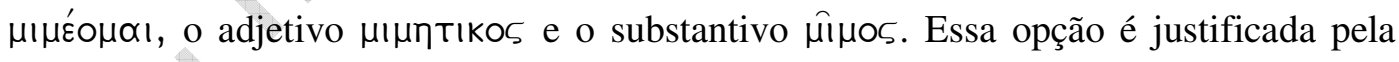
razão de que o termo "imitar" exclui o objeto produzido (tragédia, por exemplo) do

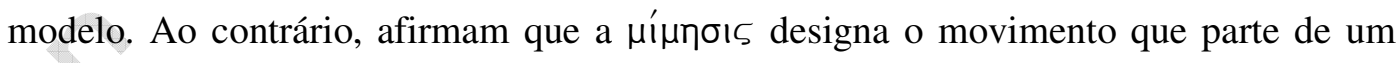

\footnotetext{
${ }^{4}$ Cf. Aristóteles, op. cit., 2007, p. 47.

${ }^{5}$ Cf. Aristóteles. Poética. Tradução e comentários de Eudoro de Souza. Brasília: Imprensa Nacional/ Casa da Moeda, s.d., p. 80 ss.

${ }^{6}$ Cf. Aristóteles, op. cit., s.d., p. 17.

${ }^{7}$ Cf. Aristóteles, op. cit., s.d., p. 88-89.

${ }^{8}$ Cf. Aristóteles, op. cit., 1980, p. 18.

${ }^{9}$ Cf. Aristóteles, op. cit., 1980, p. 17.
} 
objeto pré-existente até um "artefato poético". ${ }^{10}$ Este movimento "cria" algo novo e não esvazia o modelo.

Halliwell vê problemas nessa tradução. ${ }^{11}$ Segundo ele, podemos empregar este termo para dizer, por exemplo, que um ator representa um caráter, assim como a pintura representa um tema, ou uma peça representa uma ação. Há pequenas e importantes diferenças entre estes modos de "representar", mas todas elas estão cobertas pela família

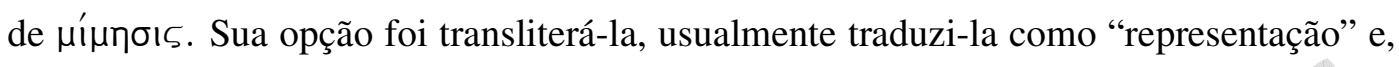
às vezes, como "retrato".

O autor entende que Aristóteles aplica todos estes significados com um status ficcional. Ele tem mais preocupações com imagens, representações e simulações da vida humana do que com argumentos e declarações da realidade. O poeta é um "dramatizador", não um intérprete da vida humana. Em sua análise dos dois primeiros capítulos da Poética, ele extrai as seguintes conclusões sobre as artes miméticas, que

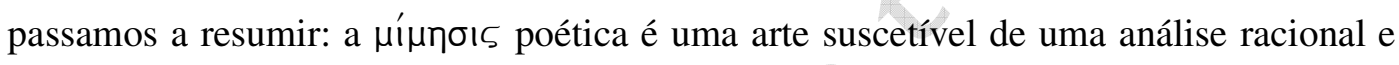
objetiva, a qual produz uma teoria de princípios, padrões e objetivos; a poesia é uma "representação" das ações humanas e da vida, que difere das outras artes pelo seu inegável caráter ético e pelo seu modo de apresentação (espetáculo); o conteúdo da

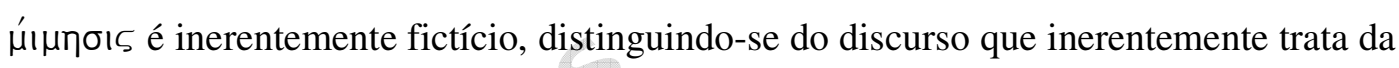

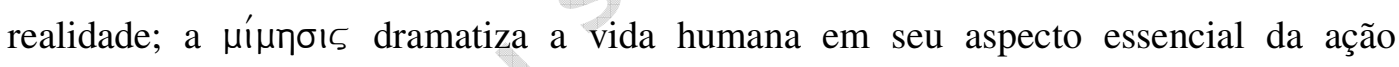
proposital e eticamente qualificada, que reflete diferentes níveis de realidade; e, por fim, ela é uma atividade ligada à aprendizagem e compreensão de realidade, que é uma necessidade humana que causa prazer.

Nós concordamos com os comentadores sobre a forte ligação da palavra $\mu$ í $\mu \eta \sigma ı$ com o teatro, e por isso adotaremos o termo "representação", ou até "re-apresentação", para traduzi-la.

No paradigma do conceito de tragédia, Aristóteles nos diz que ela é uma representação de uma ação elevada e completa e de certa extensão. Aqui ele define o objeto a ser representado. O primeiro aspecto a ressaltar é a hierarquia estabelecida da

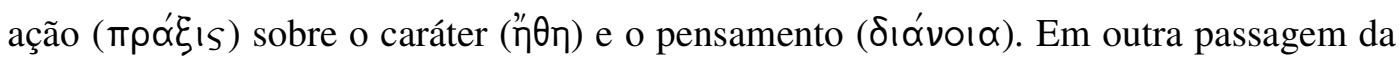
Poética, Aristóteles afirma que "a tragédia é representação não de homens, mas de

${ }^{10}$ Cf. Aristóteles, op. cit., 1980, p. 20.

${ }^{11}$ Cf. Aristotle. The Poetics of Aristotle. Translation and commentary of Stephen Halliwell. London: Duckworth, 1987, p. 71. 


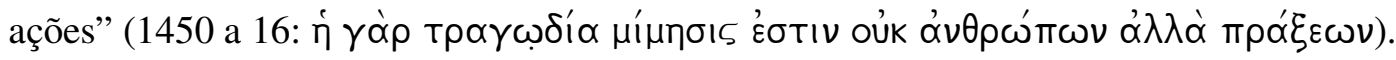
Para entender melhor o significado dessa afirmação, temos que ter em mente que a tragédia é dividida por Aristóteles em seis partes, que podemos agrupar em "objetos":

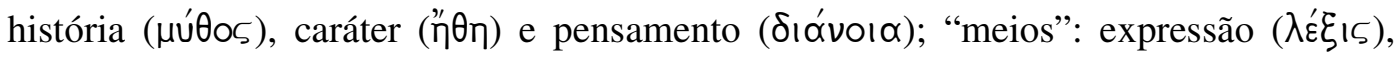

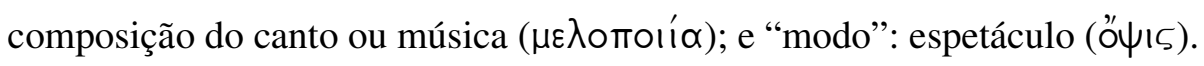

Segundo Dupont-Roc e Lallot, esta precisão "funda-se na proeminência da

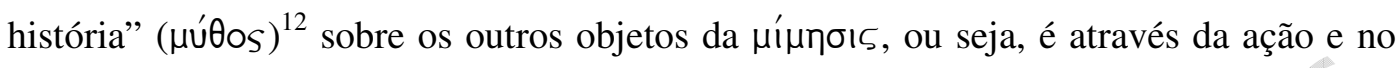
encadeamento de fatos provocados pela ação humana que o caráter e pensamento do homem podem manifestar-se. Em outras palavras, o caráter e o pensamento de um homem só podem ser conhecidos quando ele está agindo. Esses comentadores apontam para uma fragilidade dessa análise de Aristóteles, pois não existe ação sem os agentes e não há verossimilhança das ações sem uma elaboração metódica do caráter e do pensamento dos agentes, ${ }^{13}$ que são sua causa. Nesse sentido, o autor da Poética inverte a perspectiva usual da ética, que vê no agente o seu objeto de análise.

Assim, Halliwell vai dizer que há uma disjunção em Aristóteles entre motivo e intenção do caráter e sua realização na ação, ${ }^{14}$ e que, na sua visão, é mais importante a atividade do agente do que as qualidades estáticas do seu caráter. O conceito é aplicado tanto para as ações humanas individuais quanto para a totalidade da ação em um enredo.

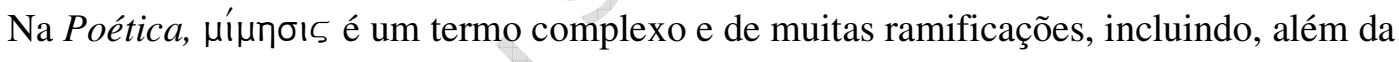
relação entre ação e ética, a relação das ações, incluindo as açsdade da aç uma fragilidade desta aniante a traduçes de um agente para com outro e a relação entre ações e sofrimento passivo. ${ }^{15}$ Nessas, a $\pi \rho \alpha \xi_{1} 15$ denota um comportamento proposital - pois é em suas ações que os homens se engajam em perseguir objetivos e realizar suas intenções - e político - pois é na esfera pública e social que ele expõe seu caráter e o seu pensamento.

No paradigma, essas ações são qualificadas, na tragédia, como elevadas e

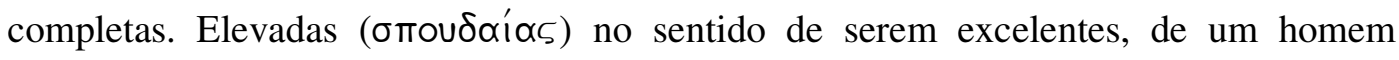

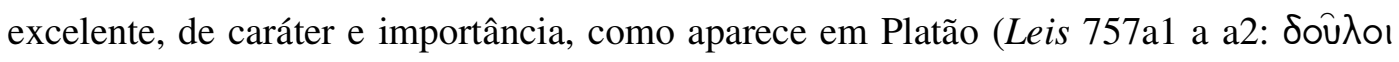

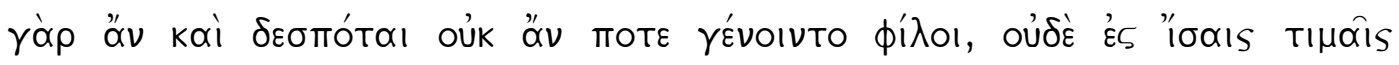

\footnotetext{
${ }^{12}$ Cf. Aristóteles, op. cit., 1980, p. 187.

${ }^{13}$ Cf. Aristóteles, op. cit., 1980, p. 19.

${ }^{14}$ Cf. Aristóteles, op. cit., 1987, p. 94.

15 Cf. Aristóteles, op. cit., 1987, p. 14-15.
} 


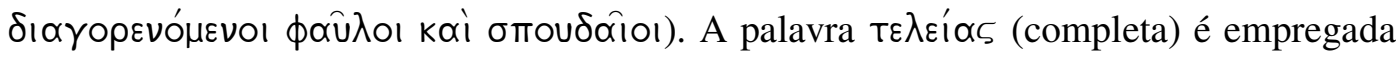
quando algo alcançou o seu final, ou seja, no sentido de que somente no quadro geral do enredo ( $\mu \hat{\cup} \theta 0 \varsigma)$ e no encadeamento de fatos resultantes dele é que a ação se realiza em todas as suas conseqüências, em toda a sua magnitude ( $\mu \dot{\varepsilon}^{\prime \varepsilon} \theta \circ \varsigma$ ). Também deriva dessa idéia que as ações devem ser encadeadas de forma racional e plausível, ou seja, as ações devem ser coerentes com o caráter e o pensamento do agente.

Depois disso determinado, Aristóteles nos diz que a representação dessas ações

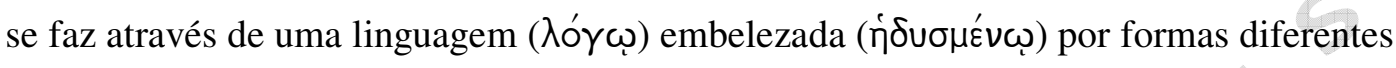
em suas diferentes partes. Aqui se faz menção aos meios da representação, e quando ele afirma que por formas diferentes está se referindo a quando há ou não o uso da música, que tem ritmo e harmonia. Com "em suas diferentes partes", ele se refere à divisão formal da tragédia (prólogo, episódios, êxodo, párodo, estásimo, lamentações, cantos do coro) em que se utiliza apenas a expressão verbal ( $\lambda \varepsilon^{\prime} \xi$ IS) ou se acrescenta o ritmo e a

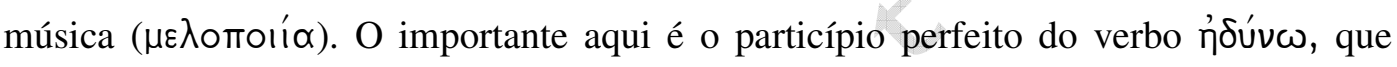
qualifica a linguagem da tragédia. Eudoro de Souza traduz como "ornamentada" e Halliwell como "enfeitada" (garnished). Dupont-Roc e Lallot a traduziram por "elevada" (relevé), mas, em suas notas, ${ }^{16}$ mostram que a palavra aparece na Retórica (1406a 19) como o sentido de tempero (assaisonnement), quando Aristóteles critica o estilo de Alcidamas, que exagera no uso de epítetos, que não os usa como tempero, mas

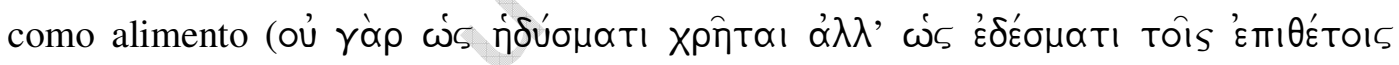

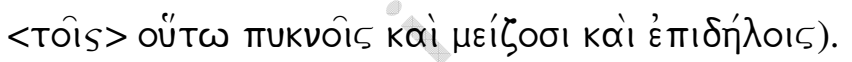

A frase seguinte reafirma o que já foi dito anteriormente, que a tragédia se serve "da ação e não da narração", e retoma a diferenciação entre a tragédia e a epopéia.

Aristóteles conclui então sua definição do gênero trágico estabelecendo mais

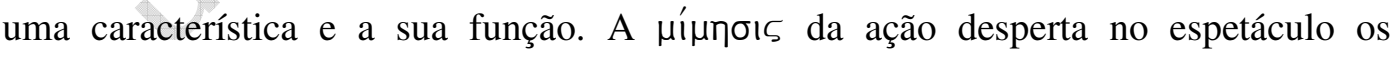

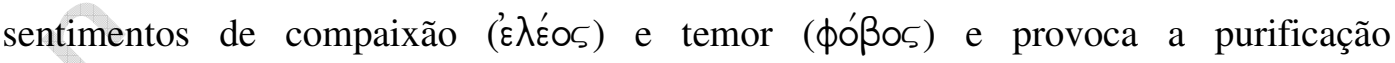
( $k \alpha \dot{\alpha} \theta \alpha \sigma ı)$ de tais paixões. Pensando no conjunto da definição, entendemos um pouco melhor a necessária caracterização dos termos anteriores, porque só com essas características é que a tragédia atingirá seu objetivo. Ou seja, Aristóteles estabelece as relações de causa e efeito da tragédia. Mas que efeito é este?

${ }^{16}$ Cf. Aristóteles, op. cit., 1980, p. 194-195. 


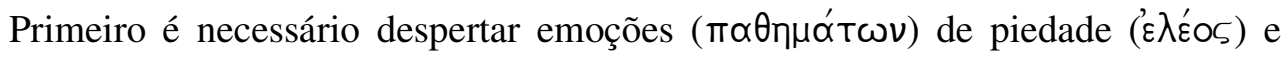

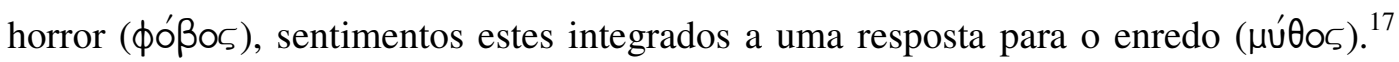

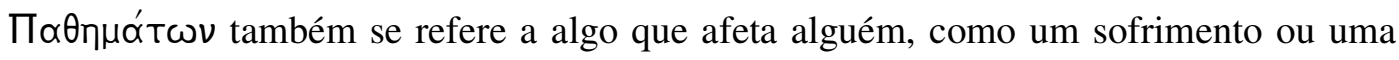

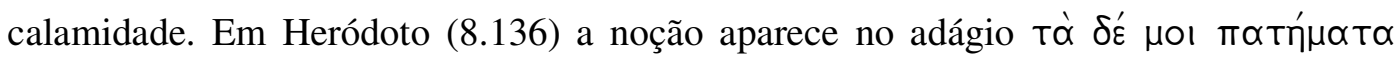

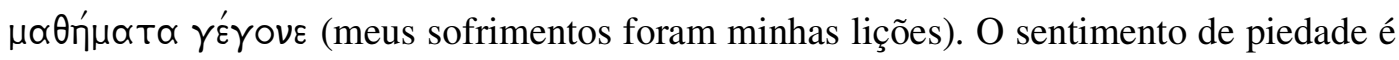
despertado quando assistimos à aflição de alguém acometido por um sofrimento imerecido; o horror é despertado quando temos a consciência de que nós também estamos expostos a tais sofrimentos. É o reconhecimento de que a tragédia dos personagens expõe a vulnerabilidade do ser humano e as condições de existência que compartilhamos com eles. ${ }^{18}$ É importante perceber que, conforme o significado que o comentador-tradutor tem da palavra $\pi \propto \theta \eta \mu \alpha$ $\tau \omega \nu$ e o contexto histórico em que está inserido, seu entendimento do que seja kó́ $\theta \alpha \rho ı \varsigma$ varia. Eudoro de Souza arrolou a trajetória da tradução desta última frase desde o século XVI até meados do século XX e temos, por exemplo, Dacier ${ }^{19}$, um autor do século XVII, que a interpretou assim:

La tragédie est donc une imitation ... qui ... par le moyen de la compassion et de la terreur, achève de purger en nous ces sortes de passions, et toutes les autres semblables.

Segundo Eudoro de Souza isso ocorre pela dificuldade de se traduzir o genitivo

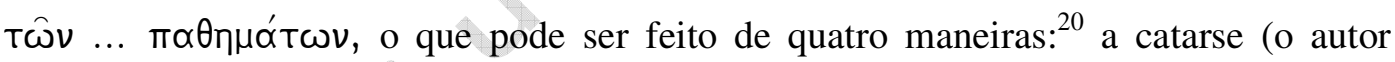
translitera a palavra) "operada por" tais emoções; a catarse "operada" por tais emoções "sobre"; a catarse "operada" por tais emoções "sobre tais emoções"; a catarse "de" tais emoções, no sentido de eliminá-las. Ele opta por entender que a kó́d purificação de tais emoções e sua função é "principalmente estética e finalmente gnósica", 21 embora não explicite bem o que seja a função gnósica, a não ser desaprovar a idéia de que podemos aprender pelo sofrimento.

Dupont-Roc e Lallot a traduzem como "depuração das emoções" e explicam que o conceito de ká日apoıs é de natureza estética, ou seja, provoca prazer e não cura de

\footnotetext{
${ }^{17}$ Cf. Aristóteles, op. cit., 1987, p. 81.

${ }^{18}$ Cf. Aristóteles, op. cit., 1987, p. 91.

19 Dacier, A. La Poétique traduite en français avec des remarques critiques. Amsterdã/Paris, 1962. Citado por Souza. Aristóteles: Poética, pág. 165.

${ }^{20}$ Cf. Aristóteles, op. cit., s.d., p. 164.

${ }^{21}$ Cf. Aristóteles, op. cit., s.d., p. 100.
} 


\section{nuntius antiquus}

natureza medicinal. ${ }^{22}$ A última interpretação seria derivada de uma leitura equivocada

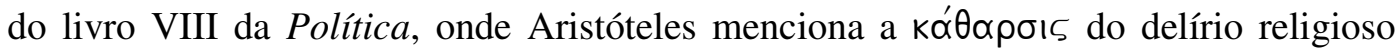
através da música e diz que o seu significado seria explicado quando ele tratasse da poesia (VIII, 1341 b 39), o que não chegou até nós. Assim, dizem esses comentadores, que, de forma positiva, "o efeito catártico da tragédia [é]: a depuração das perturbações (troubles) - terror, piedade e outras perturbações parecidas - que ela faz nascer nos espectadores, depuração que substitui o prazer pela aflição". ${ }^{23}$

No prefácio à tradução da Poética por Ana Maria Valente, Maria Helena da Rocha Pereira aponta que vários sentidos foram dados a esta palavra em particular e à função da tragédia em geral ao longo dos últimos séculos: ela já esteve no âmbito do vocabulário médico e terapêutico (“depuração", "purgação", "purificação”, "alívio”) ou religioso (através de danças violentas os coribantes obtinham a purificação do delírio, com o esgotamento do corpo), que ela serviria para a clarificação intelectual (aprendizagem e conhecimento, e daí, o prazer), ela seria um meio de se conseguir um fortalecimento emocional (próprio da época do Renascimento) e embasou as teorias moralistas (dominar ou eliminar as emoções que levam ao sofrimento). Mas ela define

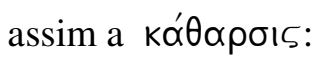

É uma doutrina com a natureza e efeitos psicológicos da experiência emocional da tragédia, e a sua presença na definição mostra que há uma forte dimensão afectiva na teoria aristotélica do gênero. ${ }^{24}$

Esta elaboração deve muito à sua concordância com análises de Halliwell, para

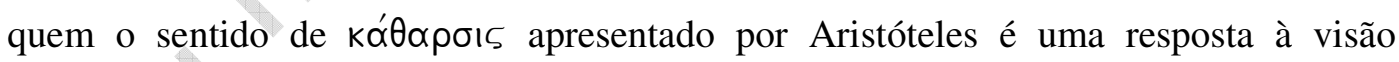
platônica da tragédia na República (X, 603-5). Ela não é, segundo ele, somente uma saída ou uma libertação de emoções, e menos ainda, como queria a erudição alemã do século XIX, uma descarga de emoções patológicas. Aristóteles a associa ao "prazer", ao papel natural que tais emoções têm na experiência e na compreensão da realidade.

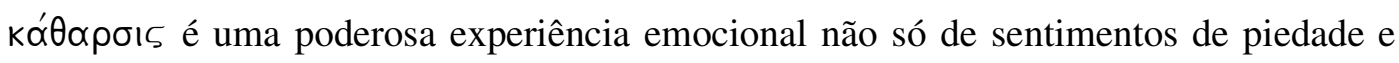

\footnotetext{
${ }^{22}$ Cf. Aristóteles, op. cit., 1987, p. 193.

${ }^{23}$ Cf. Aristóteles, op. cit., 1987, p. 189 (nossa tradução).

${ }^{24}$ Cf. Aristóteles, op. cit., 2007, p. 15.
} 
horror, "mas conduz para o funcionamento legítimo deles como parte de nossa compreensão e como resposta para os eventos do mundo humano". ${ }^{25}$

O conceito e o julgamento de Aristóteles deste gênero poético influenciaram a maneira como a civilização ocidental leu a tragédia ao longo dos séculos, quase que como se fosse um cânone. No entanto, queremos questioná-lo. Constatamos que os termos utilizados por Aristóteles para definir as emoções próprias da tragédia, escrito no século IV a.C., não corresponde inteiramente aos que os tragediógrafos do século V a.C. se serviram. Uma pesquisa quantitativa dos termos empregados por eles mostra os seguintes resultados:

\begin{tabular}{|c|c|c|c|c|}
\hline \multirow{2}{*}{ Autor } & \multicolumn{2}{|c|}{ Terror } & \multicolumn{2}{c|}{ Compaixão } \\
\cline { 2 - 5 } & $\tau \alpha^{\prime} \rho \beta \circ \varsigma$ & $\phi o ́ \beta ం \varsigma$ & $\sigma \varepsilon ́ \beta \alpha \varsigma$ & $\varepsilon^{\prime \prime} \lambda \varepsilon \circ \varsigma$ \\
\hline Ésquilo & 25 & 78 & 113 & 0 \\
\hline Sófocles & 22 & 71 & 75 & 1 \\
\hline Eurípides & 28 & 182 & 172 & 6 \\
\hline
\end{tabular}

O quadro acima revela que фóßos é uma palavra de uso comum, aparecendo com uma frequiência quase que uniforme entre os três autores, se levamos em conta que temos de Eurípides um número maior de obras. Interessante notar que o substantivo

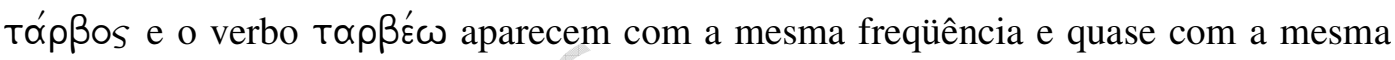
uniformidade; тópßos (terror) representa, em Ésquilo e em Sófocles, um quarto para

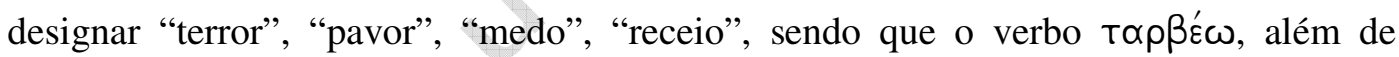
significar "assustar", "espantar" e "aterrorizar", também aparece no Bailly com o sentido de "experimentar um medo religioso, respeitar, venerar", ou seja, bem adequado

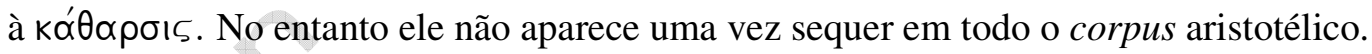

Mais impressionante ainda é em relação a "' $\lambda \varepsilon \circ \varsigma$, um substantivo não recorrente entre os tragediógrafos, pois temos apenas sete registros de seu emprego, ${ }^{26}$ o mesmo número de vezes que Aristóteles utiliza-a só na Poética. ${ }^{27}$ Em seu lugar, os trágicos

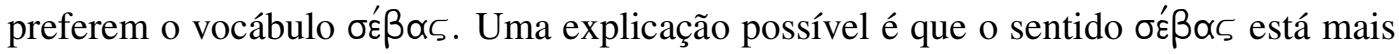
na esfera religiosa, ligada a uma piedade e um respeito para com os cultos e deuses, próprios das celebrações em que a apresentação das tragédias está inserida. $\mathrm{O}$ termo supõe uma relação hierárquica entre homens e deus, enquanto que ${ }^{\prime} \lambda \varepsilon_{\text {OOS }}$ tem um

${ }^{25}$ Cf. Aristóteles, op. cit., 1987, p. 90

${ }^{26}$ As ocorrências são: em Sófocles, no Filoctetes 308; em Euripides, uma vez nas Fenícias (1286), quatro vezes no Orestes $(333,568,832,968)$ e uma vez na Ifigênia em Aulis (491).

${ }^{27}$ No total vão aparecer 41 vezes em toda sua obra. 
sentido mais amplo e profano de piedade e compaixão, adequado para as relações entre os iguais da pólis grega.

Concluímos que, assim como nós, Aristóteles também procura respostas para sua experiência da realidade, e a expressa com a adequação de seu tempo. O que de forma nenhuma diminui a pertinência e a relevância dos seus juízos.

\section{Referências}

ARISTOTE. La Poétique. Texte, traduction et notes par Roselyne Dupont-Roc et Jean Lallot. Paris: Seuil, 1980.

. The Poetics of Aristotle. Translation and commentary of Stephen Halliwell. London: Duckworth, 1987.

. Aristotle: Poetics. Translation and commentary by D. W. Lucas. Oxford: Clarendon Press, 1968.

. A Poética de Aristóteles. Tradução e notas de Ana Maria Valente, prefácio de Maria Helena da Rocha Pereira. Lisboa: Calouste Gulbenkian, 2007.

. Poética. Tradução e comentários de Eudoro de Souza. Brasília: Imprensa Nacional/ Casa da Moeda, s.d.

BAILLY, A. Dictionnaire grec-français. Édition revue par L. Séchan et P. Chantraine. Paris: Hachette, 2000.

LIDDEL, H. G.; SCOTT, R. A Greek-English lexicon. Revised and augmented throughout by Sir Henry Stuart Jones, with the assistance of. Roderick McKenzie. Oxford: Clarendon Press, 1940.

SILK, M. S. The six parts of tragedy in Aristotle's "Poetics". Cambridge philological Society. Cambridge, n. 40, 1994, pp. 107-115. 